\title{
Patients' compliance with different administration routes for allergen immunotherapy in Germany
}

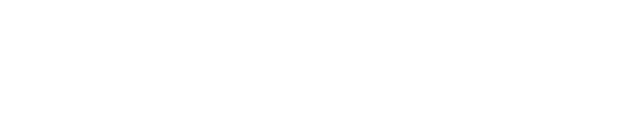

Anne-Marie Egert-Schmidt Jan-Marcel Kolbe

Sabine Mussler Susanne Thum-Oltmer

Allergopharma GmbH \& Co. KG, Reinbek, Germany
Correspondence: Anne-Marie EgertSchmidt Allergopharma GmbH \& Co., KG, Hermann-Körner-Straße 52, 2I465 Reinbek, Germany

Email anne-marie.egert-schmidt@ allergopharma.com
Background: Allergen immunotherapy (AIT) is the practice of administering gradually increasing quantities of an allergen extract to an allergic subject to ameliorate the symptoms associated with the subsequent exposure to the causative allergen. It is the only treatment that may alter the natural course of allergic diseases. According to AIT guidelines and summary of product characteristics (SmPCs), the treatment should be carried out for at least 3 years. It is controversially discussed whether subcutaneous or sublingual administration routes cause higher patients' compliance.

Methods: German sales data for different preparations of the allergen manufacturer Allergopharma $\mathrm{GmbH} \& \mathrm{Co}$. KG were retrospectively evaluated for 5 consecutive years, based on prescriptions per patient: pollen sublingual immunotherapy (SLIT) and high-dose hypoallergenic (allergoid) or unmodified depot pollen and mite preparations for subcutaneous immunotherapy (SCIT). To identify patients' compliance, “completed treatment years" were determined. A completed treatment year was defined by the required number of prescribed allergen preparations according to the recommended dosage scheme given in the respective SmPCs.

Results: Prescription data of 85,241 patients receiving pollen or mite SCIT and 706 patients receiving pollen SLIT were included in this analysis. Patients' compliance for at least 3 treatment years with high-dose hypoallergenic pollen SCIT was higher when administered perennially (60\%) compared to preseasonally (27\%). Prescriptions for at least 3 years were received from $42 \%$ of patients with pollen SCIT and from $45 \%$ of patients with mite SCIT. Compliance with SLIT was lowest with only $16 \%$ of patients receiving prescriptions for at least 3 treatment years. Children and adolescents were more compliant than adults, independent of whether they received SLIT or SCIT.

Conclusion: In general, patients' compliance with SCIT using high-dose hypoallergenic or unmodified depot preparations was higher than with pollen SLIT. Perennial application of SCIT seems to increase compliance in comparison to the preseasonal application. Children and adolescents were most compliant, independent of the preparation applied.

Keywords: compliance, real-life data, sublingual immunotherapy, subcutaneous immunotherapy, high-dose hypoallergenic preparation, preseasonal immunotherapy, perennial immunotherapy

\section{Introduction}

Allergic rhinoconjunctivitis affects between $10 \%$ and $30 \%$ of the world population, and studies indicate that prevalence rates are increasing worldwide. ${ }^{1}$ Its treatment is based on patient education, environmental control and allergen avoidance, pharmacotherapy, and allergen immunotherapy (AIT). ${ }^{1}$ AIT is the practice of administering gradually increasing quantities of an allergen extract to an allergic subject to ameliorate the symptoms associated with the subsequent exposure to the causative allergen. ${ }^{2}$ It is accepted to be the only causal treatment option that is able to induce an immune 
tolerance against allergens, and it should be performed for at least 3 years. ${ }^{3,4}$ For this reason, compliance with AIT is mandatory, as happens for all chronic medical treatment. Subcutaneous immunotherapy (SCIT) represents the standard modality of treatment while the sublingual application (sublingual immunotherapy [SLIT]) is meanwhile accepted as an alternative ${ }^{1}$ - mainly for new high-dose grass pollen preparations. SCIT is administered in the physicians' practice while SLIT can be taken by patients themselves at home. Both treatment options seem to have advantages concerning patients' acceptance: patients receiving SCIT are regularly seen by their physicians who can answer all their questions while SLIT is favorable in patients with time-consuming jobs or activities (eg, sports, traveling).

"Drugs don't work in patients who don't take them." This phrase by C Everett Koop, MD, Surgeon General of the United States from 1982 to 1989, sums up how important it is that patients stay the course of any drug. Few physicians would doubt that the efficacy of a medication itself and patient compliance with the therapeutic regimen both influence the effectiveness of a treatment regimen.

In guidelines dealing with therapy of allergic rhinoconjunctivitis, antihistamines or topical corticosteroids are recommended as the first-line treatment while AIT is only indicated when pharmacotherapy insufficiently controls symptoms. ${ }^{2}$ For asthma treatment, the current guidelines recommend AIT even more reluctant. ${ }^{5}$ It is generally assumed that pharmacotherapy shows an immediate onset of action, whereas AIT must be applied longer to achieve symptom relief. In contrast to that, new data based on meta-analyses evidenced indirectly but consistently that SCIT is at least as potent as pharmacotherapy such as antihistamines, nasal corticosteroids, or leukotriene antagonists in controlling symptoms of seasonal allergic rhinitis as early as in the first treatment season. ${ }^{6}$ This effect is claimed as "treatment of allergic symptoms" by the Guideline on the clinical development of products for specific immunotherapy for the treatment of allergic diseases by the European Medicines Agency. ${ }^{7}$ Additional benefits of SCIT are its "sustained effect" (during 2 years or 3 years treatment) ${ }^{8-11}$ and "longterm and disease-modifying efficacy" (eg, prevention of new sensitizations and asthma). ${ }^{12-14}$ According to guidelines, a therapy of at least 3 consecutive years is required to achieve the latter effect. ${ }^{4}$ Lack of compliance is even a contraindication for AIT. ${ }^{15}$ Allergen-specific immunotherapy should be performed for at least 3 years but many patients stop it prematurely and are therefore noncompliant. The same problem applies to the treatment of other chronic diseases such as epilepsy (noncompliance 46\%-88\%), diabetes (66\%-85\%), hypertension (39\%-93\%), or asthma (37\%-92\%). ${ }^{16}$

The aim of this sales data analysis was to investigate "real life" compliance to SCIT and SLIT in German patients receiving preparations from Allergopharma $\mathrm{GmbH} \& \mathrm{Co}$, KG, Reinbek, Germany.

\section{Methods}

For safety reasons, Allergopharma labels all AIT products in Germany with the patient's name independently of the product's registration status. Therefore, it can be exactly backtracked how many prescriptions each patient has received. Sales data from the Allergopharma enterprise resource planning system (ERP Blending) were analyzed for patients (children, adolescents, and adults) starting SCIT with high-dose hypoallergenic pollen $\left(\right.$ Allergovit ${ }^{\circledR}$ ) or house dust mite preparations $\left(\right.$ Acaroid $\left.^{\circledR}\right)$, unmodified pollen or mite (house dust mites and storage mites) preparations (NovoHelisen ${ }^{\circledR}$ Depot), or SLIT with high-dose pollen preparations (AllerSlit ${ }^{\circledR}$ forte) in Germany. We selected sales data for patients who received their first prescription for SCIT or SLIT in 2007, and we wanted to compare compliance of both administration routes. There was no selection with regard to patients' characteristics, specialization or size of practice of the prescribing physician, allergen(s) administered, or different parts of the country where physicians' budgets for medications may vary. To identify patients' compliance, the number of prescriptions per patient during a 5-year period (2007-2011) was evaluated and based on this "completed treatment years" were determined. A "completed treatment year" was defined by the required number of prescribed packages according to the recommended dosage scheme of each preparation, as specified in the respective summary of product characteristics (SmPCs) (Table 1). The high-dose hypoallergenic pollen preparation Allergovit ${ }^{\circledR}$ may be administered preseasonally (with seven injections within 6 weeks before the respective pollen season for 3 consecutive years) or perennially (updosing with the preseasonal scheme followed by maintenance therapy every 4-5 weeks for 3 consecutive years). A patient was defined as treated "preseasonally" when he/she received only initial treatment packages over the years. In this case, at least one initial treatment package was necessary per "completed treatment year" to be defined as compliant (Table 1). A patient was defined as "perennially" treated with Allergovit ${ }^{\circledR}$ when additionally at least one later maintenance package was prescribed. SCIT with the high-dose hypoallergenic mite preparation Acaroid ${ }^{\circledR}$ as well as SCIT with the unmodified pollen or mite preparation 
Table I Definition of "completed treatment years" according to the number of AIT prescriptions per patient

\begin{tabular}{lllll}
\hline Completed treatment years & & $\geq$ year & $\geq 2$ years & $\geq 3$ years \\
\hline Number of prescriptions $(\mathrm{Rx})^{*}$ & Preseasonal SCIT & $\geq \mathrm{IRx}$ & $\geq 2 \mathrm{Rx}$ & $\geq 3 \mathrm{Rx}$ \\
& Perennial SCIT & $\geq 2 \mathrm{Rx}$ & $\geq 5 \mathrm{Rx}$ & $\geq 5 \mathrm{Rx}$ \\
& SLIT & $\geq 2 \mathrm{Rx}$ & $\geq 8 \mathrm{Rx}$ \\
\hline
\end{tabular}

Note: *Maintenance treatment sets containing two vials were counted as two units.

Abbreviations: AIT, allergen immunotherapy; SCIT, subcutaneous immunotherapy; SLIT, sublingual immunotherapy.

Novo-Helisen ${ }^{\circledR}$ Depot are administered perennially. For perennial SCIT, a higher number of prescriptions were necessary per "completed treatment year" (Table 1); therefore, maintenance treatment sets containing two vials were counted as two units. High-dose pollen SLIT with AllerSlit ${ }^{\circledR}$ forte is also administered perennially. As it is taken at home every day by the patient, the number of required prescriptions is highest (Table 1).

Patients' compliance was additionally evaluated for the three age groups: children (2-11 years), adolescents (12-17 years), and adults (18 years and older). The age groups were defined according to the ICH E11 guideline Clinical Investigation of Medicinal Products in the Paediatric Population. ${ }^{17}$ But there were no children under 5 years of age in our database, as children under 5 years of age are normally not considered as suitable candidates for AIT..$^{15}$ This is in accordance with Article 45 of the Pediatric Regulation of the Co-ordination Group for Mutual Recognition and Decentralised Procedures - Human (CMDh) ${ }^{18}$

Prescription data from 85,241 patients receiving SCIT with high-dose hypoallergenic or unmodified pollen or mite preparations and 706 patients receiving SLIT with high-dose pollen preparations were included in this analysis (Table 2).

\section{Results}

Figure 1 shows results for patients' compliance (\%) described as "completed treatment years" (within 2007-2011) with SCIT or SLIT receiving pollen (Figure 1A) or mite preparations (Figure 1B).

Patients' compliance decreased from year to year independently of the preparation or dosage scheme. Patients under SCIT with the high-dose hypoallergenic mite preparation did seem to show slightly lower compliance rates than with the respective pollen preparation. For unmodified SCIT preparations, the compliance rates for at least 3 treatment years were $42 \%$ for pollen and $45 \%$ for mite preparations.

The compliance rate with pollen SLIT was the lowest: $47 \%$ of patients discontinued therapy within the first treatment year, $26 \%$ of patients were compliant for at least
2 years, and only $16 \%$ of patients received prescriptions for at least 3 treatment years, as recommended (Figure 1).

Compliance with SCIT with high-dose hypoallergenic pollen preparations was higher when administered perennially than preseasonally (Figure 2).

Comparing perennial application of pollen preparations (high-dose hypoallergenic SCIT, unmodified SCIT and SLIT) shows that compliance with SCIT was obviously twofold to nearly fourfold higher than with SLIT in the third treatment year (Figure 3).

We also investigated the aspect whether there are different compliance rates with different pollen allergens, eg, grass pollen (long pollination period from May to September) vs tree pollen (short pollination period from March to May) (data not shown). We could not find any difference between the groups.

Patients' age seemed to influence compliance with AIT. Table 3 shows detailed results for compliance with the various preparations in three different age groups including children (5-11 years), adolescents ( $12-17$ years), and adults ( $\geq 18$ years). Children were always most compliant independent of the preparation and the treatment year, while adults showed lowest compliance rates. Nevertheless, patients' compliance in the three different age groups reflected the same pattern like in the total population: compliance with high-dose hypoallergenic pollen SCIT was higher when administered perennially than preseasonally; compliance with high-dose hypoallergenic mite or unmodified pollen and mite SCIT was slightly lower than with perennial highdose hypoallergenic pollen SCIT; and compliance with SLIT was the lowest.

Moreover, the compliance in patients treated by pediatricians was higher compared to other physicians, with the same tendencies for SCIT vs SLIT (data not shown).

\section{Discussion}

Compliance is the degree of constancy and accuracy with which a patient follows a prescribed regimen. ${ }^{19}$ Patients' compliance is one critical aspect concerning the full benefit of medications that can be achieved only if patients follow 
Table 2 Number of patients receiving prescriptions for SCIT or SLIT included in the analysis

\begin{tabular}{|c|c|c|c|c|}
\hline & Total (any age) & 5-II years & $12-17$ years & $\geq 18$ years \\
\hline \multicolumn{5}{|c|}{ SCIT with high-dose hypoallergenic preparations (allergoids) } \\
\hline Pollen, perennial & 19,539 & 521 & 2,952 & 16,066 \\
\hline Pollen, preseasonal & 44,355 & 749 & 5,030 & 38,576 \\
\hline Mites & 9,952 & 339 & $\mathrm{I}, 890$ & 7,723 \\
\hline \multicolumn{5}{|c|}{ SCIT with unmodified preparations } \\
\hline Pollen, perennial & 7,758 & 125 & 922 & 6,711 \\
\hline Mites & 3,637 & 123 & 640 & 2,874 \\
\hline \multicolumn{5}{|l|}{ SLIT } \\
\hline Pollen & 706 & 43 & 93 & 570 \\
\hline
\end{tabular}

Abbreviations: SCIT, subcutaneous immunotherapy; SLIT, sublingual immunotherapy.

prescribed treatment regimens reasonably closely. ${ }^{19}$ Noncompliance to treatment is a worldwide problem especially in long-term regimens..$^{20,21}$

Lack of compliance is one of the contraindications for AIT since treatment should be performed for 3 years. ${ }^{15}$ Though allergic symptoms and intake of rescue medication are already reduced in the first treatment year, only a full course of 3 years of AIT is able to induce increasing efficacy and long-term benefits, and to alter the natural course of allergic diseases. So it was shown that a second- and thirdtreatment year of grass pollen SCIT was able to increase efficacy ${ }^{9,22}$ and that the duration of efficacy after house dust mite SCIT depends upon the duration of therapy. ${ }^{23}$ Various trials showed long-term and disease-modifying effects after a 3 years' course of SCIT with reduced symptoms and medication need, ${ }^{12,13,24}$ reduced asthma prevalence, ${ }^{14}$ or reduced onset of new sensitizations ${ }^{12,25}$ for up to 12 years after terminating SCIT.

Since it was shown that greater perceived disease severity is associated with better compliance with medications, ${ }^{26}$ one problem might be that allergic diseases are often trivialized.
Patients' expectations are dependent on their knowledge of allergic diseases and the relevant treatment options. Some European surveys showed that most patients with allergic rhinitis were unaware that they are suffering from a medical condition that could be treated successfully. ${ }^{27-29}$ Only one-third has sought help from a health professional. The awareness of AIT was very low, and only $21 \%$ of patients were offered AIT in France. ${ }^{27}$ Moreover, most patients with allergic diseases consult primary care instead of allergy specialists. ${ }^{30}$ According to a large patient sample survey of allergic disorders in Germany, only $7 \%$ of patients with rhinitis and $5 \%$ of patients with allergic asthma received AIT, mostly performed by specialists. ${ }^{31}$

There is still a controversial debate whether SCIT or SLIT might result in higher compliance. Some argue that SLIT with taking the medication at home might improve patients' compliance, while others assume that the regular visits at the physicians' practice for the injections of SCIT provides better compliance. ${ }^{32,33}$

Compliance with treatment is known to be far better in randomized controlled trials than in "real life". ${ }^{19,34}$ Therefore,
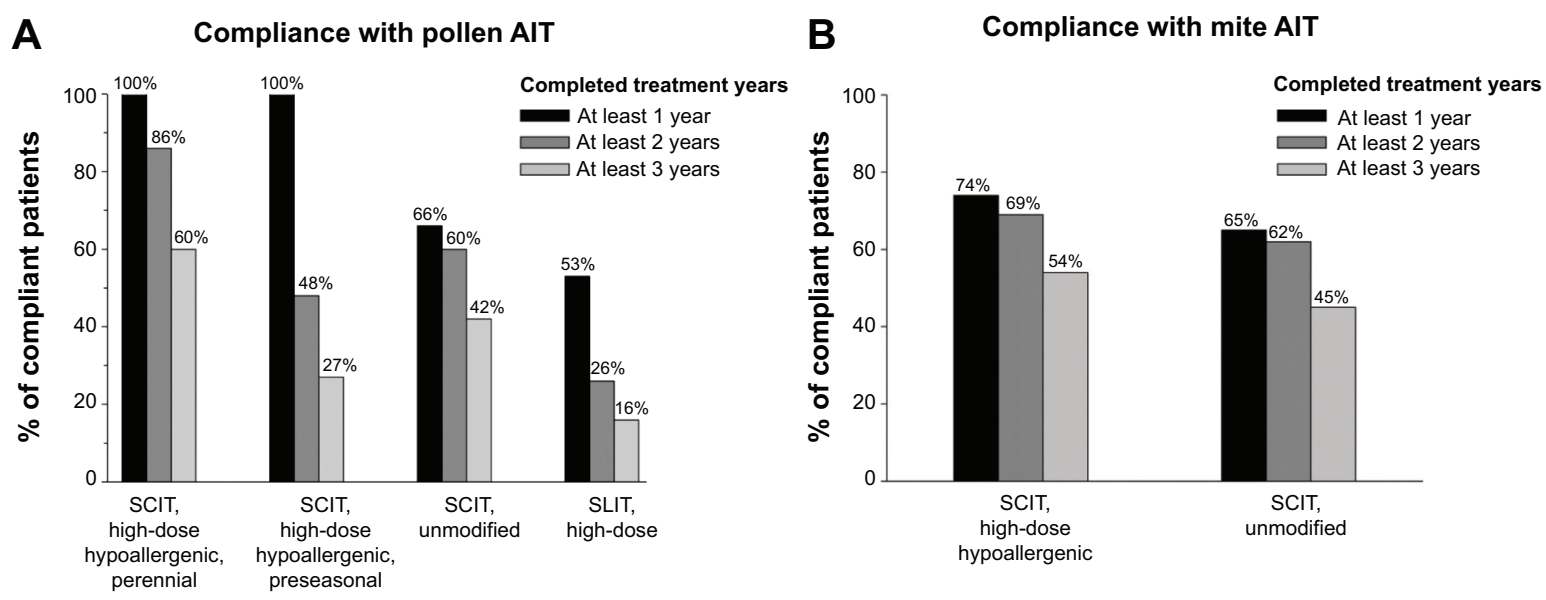

Figure I Patients' compliance with pollen (A) or mite (B) AIT.

Abbreviations: AIT, allergen immunotherapy; SCIT, subcutaneous immunotherapy; SLIT, sublingual immunotherapy. 


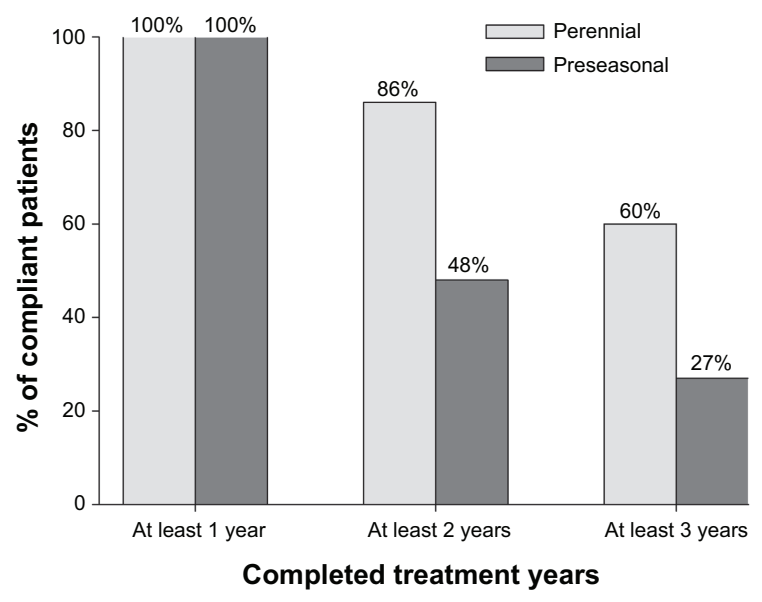

Figure 2 Compliance with high-dose hypoallergenic pollen SCIT administered perennially or preseasonally.

Abbreviation: SCIT, subcutaneous immunotherapy.

we used Allergopharma sales data to evaluate patients' compliance with AIT in the daily practice.

To our knowledge, this survey is the largest one investigating patients' compliance with AIT evaluating "real life" sales data of more than 85,000 patients. But as it only focuses on sales data, it has some limitations. The Allergopharma database is a prescription database that does not contain any information about patients' medical history and previous or additional medications. Thus, it is impossible to verify if the AIT groups were matched - eg, for clinical characteristics - when starting AIT. There were far more SCIT patients than SLIT patients in the evaluation because of the later market access of the SLIT preparation. Besides, no prescription implies that the patient really started and/ or finished the respective prescribed package(s). There is a lack of definition in the group with application of highdose hypoallergenic pollen preparations. For this group, it is stated that $100 \%$ of preseasonally and perennially treated

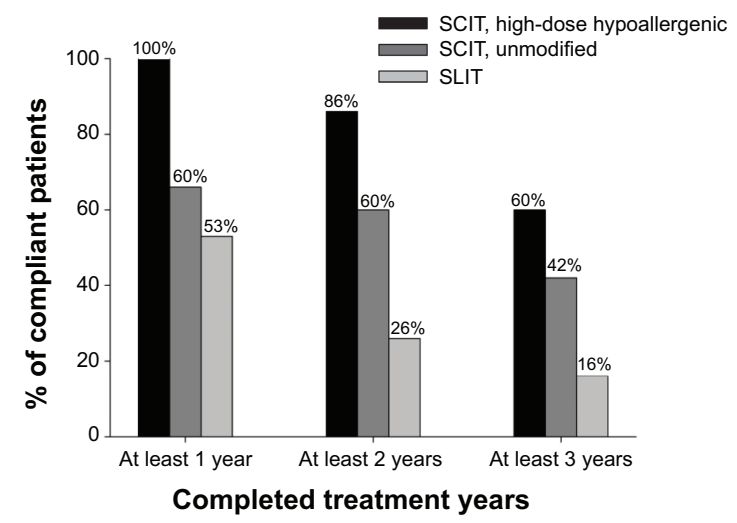

Figure 3 Compliance with perennially applied high-dose hypoallergenic pollen SCIT, unmodified pollen SCIT and pollen SLIT.

Abbreviations: SCIT, subcutaneous immunotherapy; SLIT, sublingual immunotherapy.
Table 3 Percentage number of patients completing at least I, 2, or 3 treatment years with the different SCIT or SLIT preparations in children 5-II years, adolescents $12-17$ years, and adults 18 years and older

\begin{tabular}{|c|c|c|c|}
\hline $\begin{array}{l}\text { Treatment } \\
\text { scheme }\end{array}$ & $\begin{array}{l}\text { At least } \\
\text { I year }\end{array}$ & $\begin{array}{l}\text { At least } \\
2 \text { years }\end{array}$ & $\begin{array}{l}\text { At least } \\
3 \text { years }\end{array}$ \\
\hline \multicolumn{4}{|c|}{ SCIT with high-dose hypoallergenic preparations } \\
\hline \multicolumn{4}{|l|}{ Pollen, perennial } \\
\hline $5-11$ years & $100 \%$ & $93 \%$ & $73 \%$ \\
\hline $12-17$ years & $100 \%$ & $91 \%$ & $68 \%$ \\
\hline$\geq 18$ years & $100 \%$ & $85 \%$ & $58 \%$ \\
\hline \multicolumn{4}{|c|}{ Pollen, preseasonal } \\
\hline $5-11$ years & $100 \%$ & $61 \%$ & $44 \%$ \\
\hline $12-17$ years & $100 \%$ & $57 \%$ & $36 \%$ \\
\hline$\geq 18$ years & $100 \%$ & $47 \%$ & $26 \%$ \\
\hline \multicolumn{4}{|l|}{ Mites } \\
\hline $5-11$ years & $83 \%$ & $77 \%$ & $65 \%$ \\
\hline $12-17$ years & $81 \%$ & $76 \%$ & $64 \%$ \\
\hline$\geq 18$ years & $72 \%$ & $67 \%$ & $51 \%$ \\
\hline \multicolumn{4}{|c|}{ SCIT with unmodified preparations } \\
\hline \multicolumn{4}{|l|}{ Pollen, perennial } \\
\hline $5-11$ years & $77 \%$ & $72 \%$ & $57 \%$ \\
\hline $12-17$ years & $73 \%$ & $67 \%$ & $49 \%$ \\
\hline$\geq 18$ years & $64 \%$ & $58 \%$ & $41 \%$ \\
\hline \multicolumn{4}{|l|}{ Mites } \\
\hline $5-11$ years & $80 \%$ & $77 \%$ & $57 \%$ \\
\hline $12-17$ years & $74 \%$ & $71 \%$ & $58 \%$ \\
\hline$\geq 18$ years & $62 \%$ & $59 \%$ & $42 \%$ \\
\hline \multicolumn{4}{|l|}{ SLIT } \\
\hline \multicolumn{4}{|l|}{ Pollen } \\
\hline $5-11$ years & $61 \%$ & $33 \%$ & $23 \%$ \\
\hline $12-17$ years & $54 \%$ & $30 \%$ & $17 \%$ \\
\hline$\geq 18$ years & $52 \%$ & $25 \%$ & $15 \%$ \\
\hline
\end{tabular}

Abbreviations: SCIT, subcutaneous immunotherapy; SLIT, sublingual immunotherapy.

patients completed at least 1 treatment year. A "preseasonal patient" is defined compliant for at least 1 year, when he/she gets at least one initial treatment package (Table 1). Preseasonal dropouts during the first year could not be detected as single injections could not be backtracked. Furthermore, patients who should be initially treated perennially, but stopped therapy after receiving one initial treatment package, were not reported as "perennial dropouts" during the first year, but as "preseasonal compliant" patients for at least 1 treatment year. So, the percentage of compliance in the first year might have been overestimated. Therefore, the first year's data of the high-dose hypoallergenic pollen preparations should not be directly compared with the other groups. For all other preparations, this lack of definition did not apply (Figure 1).

The results on hand indicate that compliance with SCIT is higher than with SLIT independent of whether unmodified or high-dose hypoallergenic SCIT preparations were used, or SCIT was administered preseasonally or perennially. This is in accordance with other surveys conducted in Germany and 
the Netherlands based on real-life data comparing compliance with SCIT and SLIT. ${ }^{34,35}$ These and another survey in Italy even found an alarming rate of SLIT discontinuation, which was up to $90 \%$ at 3 years after prescription. ${ }^{35,36}$ In contrast, another German investigation based on a national prescription database (INSIGHT Health) showed higher compliance rates with grass pollen SLIT than with grass pollen SCIT over 3 years on a per-patient basis. ${ }^{32}$ This deviating result might be caused by a different compliance definition in that survey: patients were identified as "persistent" if they renewed their prescription at least once a year, which is not in accordance with the SmPC of the mentioned products. The survey on hand demanded clearly stricter criteria with an obviously higher number of necessary prescriptions per year. This aspect is of special importance if we consider that only the dosage scheme given in the SmPC is the one with proven efficacy in clinical studies.

In our survey with more than 13,500 patients starting mite SCIT with high-dose hypoallergenic and unmodified preparations in 2007 compliance was 54\% and 45\%, respectively, for at least 3 treatment years. Comparable results based on sales data for SLIT with mite preparations in Italy were less than $30 \%{ }^{36}$ confirming our results that compliance with SCIT is higher than with SLIT regardless of prescribing pollen or mite preparations.

A 2-year follow-up survey of children' compliance with SLIT showed that withdrawal rate decreased with the number of visits per year. ${ }^{37}$ Adequate compliance was reached only in patients called for visits four times per year. Therefore, the pivotal measure to enhance compliance seems to be the frequent control of allergic patients by the physician himself. Similarly, in the analysis on hand, compliance with high-dose hypoallergenic pollen SCIT was higher when administered perennially than preseasonally. This indicates that the perennial treatment schedule seems to allow an improved patient management and may therefore lead to improved patient compliance compared to the preseasonal treatment scheme. Additionally, perennial SCIT with the high-dose hypoallergenic grass pollen preparation Allergovit ${ }^{\circledR}$ was recently shown to be more effective than the preseasonal application in a double-blind, double-dummy trial with reaching significance in the third treatment year. ${ }^{38}$ Therefore, perennial SCIT with high-dose hypoallergenic pollen preparations resulting in more frequent patient-doctor contacts seems to be favorable to achieve higher compliance with higher efficacy. Physicians have a key role in improving patients' compliance.

To our knowledge, this survey is the first comparing patients' compliance with AIT of children (5-11 years), adolescents (12-17 years), and adults (18 years and older). Interestingly, children' compliance was highest while that of adults was lowest. Good compliance among children and adolescents was also found in a smaller study. ${ }^{39}$ This is in contrast to results with other medication showing that compliance in general is lower among children and adolescents than in adults. ${ }^{40}$ It is well known that genetic factors influence development of allergic diseases, and a high proportion of parents of allergic children also suffer from allergic diseases. ${ }^{2} \mathrm{We}$ therefore assume that parents' own experiences and disease burden might motivate them to ensure that their children are compliant with AIT. So, they care for that their children follow the prescribed dosage regimen with SLIT at home and they even accompany their child to every injection when receiving SCIT. In general, education of the patient on allergic disease management is essential. Such education and the resulting preferences of patients for certain treatment regimes, which should be respected if possible, are likely to maximize compliance and optimize treatment outcomes. ${ }^{2,41}$

Based on Allergopharma sales data from the German market, we conclude that perennial treatment with high-dose hypoallergenic pollen SCIT seems to be the treatment scheme with the highest patient compliance rates. In addition, SCIT with hypoallergenic or unmodified preparations appears to be superior to SLIT application. Children aged 5-11 years showed the highest compliance rates independent of the preparation applied.

\section{Disclosure}

The authors are employees of Allergopharma GmbH \& Co. $\mathrm{KG}$. The authors report no other conflicts of interest in this work.

\section{References}

1. World Allergy Organization. WAO White Book on Allergy. 1 ed. Milwaukee: World Allergy Organization; 2011.

2. Bousquet J, Khaltaev N, Cruz AA, et al. Allergic Rhinitis and its Impact on Asthma (ARIA) 2008 update (in collaboration with the World Health Organization, GA(2)LEN and AllerGen). Allergy. 2008;63:8-160.

3. Akdis CA, Akdis M. Mechanisms of allergen-specific immunotherapy. J Allergy Clin Immunol. 2011;127:18-27.

4. Brehler R, Klimek L, Kopp MV, Virchow JC. Specific immunotherapy. Indication and mode of action. Dtsch Ärztebl Int. 2013;110:148-159.

5. Global Initiative for Asthma (GINA). Global strategy for asthma management and prevention 2014. Vancouver, WA: Global Initiative for Asthma (GINA); 2014. Available from: http://www.ginasthma.org/ documents/4. Accessed October 2, 2014.

6. Matricardi PM, Kuna P, Panetta V, Wahn U, Narkus A. Subcutaneous immunotherapy and pharmacotherapy in seasonal allergic rhinitis: A comparison based on meta-analyses. J Allergy Clin Immunol. 2011;128: 791-799.

7. European Medicines Agency CHMP/EWP/18504/2006. Guideline on the Clinical Development of Products for Specific Immunotherapy for the Treatment of Allergic Diseases. European Medicines Agency (EMEA). Committee for Medicinal Products for Human Use (CHMP); 2008. Available from: http://www.ema.europa.eu/docs/en_GB/document_library/ Scientific_guideline/2009/09/WC500003605.pdf. Accessed October 16, 2014 
8. Corrigan CJ, Kettner J, Doemer C, Cromwell O, Narkus A. Efficacy and safety of preseasonal-specific immunotherapy with an aluminiumadsorbed six-grass pollen allergoid. Allergy. 2005;60:801-807.

9. Williams A, Henzgen M, Rajakulasingam K. Additional benefit of a third year of specific grass pollen allergoid immunotherapy in patients with seasonal allergic rhinitis. Eur Ann Allergy Clin Immunol. 2007;39: 123-125.

10. Zielen S, Kardos P, Madonini E. Steroid-sparing effects with allergenspecific immunotherapy in children with asthma: a randomized controlled trial. J Allergy Clin Immunol. 2010;126:942-949.

11. Kuna P, Kaczmarek J, Kupczyk M. Efficacy and safety of immunotherapy for allergies to Alternaria alternata in children. $J$ Allergy Clin Immunol. 2011;127:502-508.

12. Eng PA, Borer-Reinhold M, Heijnen IAFM, Gnehm HPE. Twelve-year follow-up after discontinuation of preseasonal grass pollen immunotherapy in childhood. Allergy. 2006;61:198-201.

13. Dominicus R. 3-years' long-term effect of subcutaneous immunotherapy (SCIT) with a high-dose hypoallergenic 6-grass pollen preparation in adults. Eur Ann Allergy Clin Immunol. 2012;44:135-140.

14. Jacobsen L, Niggemann B, Dreborg S, et al. Specific immunotherapy has long-term preventive effect of seasonal and perennial asthma: 10-year follow-up on the PAT study. Allergy. 2007;62:943-948.

15. Alvarez-Cuesta E, Bousquet J, Canonica GW, Durham SR, Malling HJ, Valovirta E. Standards for practical allergen-specific immunotherapy. Allergy. 2006;61:1-20.

16. Claxton AJ, Cramer J, Pierce C. A systematic review of the associations between dose regimens and medication compliance. Clin Ther 2001;23:1296-1310

17. European Medicines Agency. ICH Topic E 11, Clinical investigation of medicinal products in the paediatric population. London: European Medicines Agency; 2001. Available from: http://www.ema.europa. eu/docs/en_GB/document_library/Scientific_guideline/2009/09/ WC500002926.pdf. Accessed October 2, 2014.

18. European Medicines Agency. EMA/PDCO standard pediatric investigation plan for allergen products for specific immunotherapy - Revision 3. London: European Medicines Agency; 2013. Available from: http:// www.ema.europa.eu/docs/en_GB/document_library/Regulatory_and_ procedural_guideline/2009/11/WC500015814.pdf. Accessed October 2, 2014.

19. Bousquet J, Demoly P. Compliance and convenience to immunotherapy. Arb Paul Ehrlich Inst Bundesamt Sera Impfstoffe Frankf A M. 2009;96:289-295.

20. Koberlein J, Kothe AC, Schaffert C. Determinants of patient compliance in allergic rhinoconjunctivitis. Curr Opin Allergy Clin Immunol. 2011 11:192-199.

21. Passalacqua G, Baiardini I, Senna G, Canonica GW. Adherence to pharmacological treatment and specific immunotherapy in allergic rhinitis. Clin Exp Allergy. 2013;43:22-28.

22. Giovannini M, Braccioni F, Sella G, et al. Comparison of allergen immunotherapy and drug treatment in seasonal rhinoconjunctivitis: a 3-years study. Eur Ann Allergy Clin Immunol. 2005;37:69-71.

23. Des Roches A, Paradis L, Knani J, et al. Immunotherapy with a standardized Dermatophagoides pteronyssinus extract. V. Duration of the efficacy of immunotherapy after its cessation. Allergy. 1996;51: 430-433.

24. Kettner J, Mussler S, Häfner D, Narkus A. Considerable 6 years post treatment long-term effect of pre-seasonal subcutaneous specific immunotherapy (SCIT) with a high-dose hypoallergenic grass pollen preparation. Allergy. 2011;66(suppl 94):S296
25. Pajno GB, Barberio G, De Luca F, Morabito L, Parmiani S. Prevention of new sensitizations in asthmatic children monosensitized to house dust mite by specific immunotherapy. A six-year follow-up study. Clin Exp Allergy. 2001;31:1392-1397.

26. DiMatteo MR, Haskard KB, Williams SL. Health beliefs, disease severity, and patient adherence: a meta-analysis. Med Care. 2007;45: 521-528.

27. Demoly P, Didier A, Mathelier-Fusade P, et al. Physician and patient survey of allergic rhinitis in France: perceptions on prevalence, severity of symptoms, care management and specific immunotherapy. Allergy. 2008;63:1008-1014.

28. Chivato T, Dahl R, de Monchy J, Valovirta E, Jacobsen L, Jarish R. Allergy: living and learning: level of knowledge (causes and medication) and primary sources of advice and information. Allergy. 2009; 62(suppl 83):S89.

29. Kalpaklioglu AF, Kalkan IK, Akcay A, et al. (Un) Awareness of allergy. World Allergy Organ J. 2011;4:170-178.

30. Ryan D, van Weel C, Bousquet J, et al. Primary care: the cornerstone of diagnosis of allergic rhinitis. Allergy. 2008;63:981-989.

31. Biermann J, Merk HF, Wehrmann W, Klimek L, Wasem J. Allergic disorders of the respiratory tract - findings from a large patient sample in the German statutory health insurance system. Allergo J. 2013;22: 366-373.

32. Sieber J, De Geest S, Shah-Hosseini K, Mösges R. Medication persistence with long-term, specific grass pollen immunotherapy measured by prescription renewal rates. Curr Med Res Opin. 2011;27:855-861.

33. Incorvaia $\mathrm{C}$, Mauro $\mathrm{M}$, Ridolo E, et al. Patient's compliance with allergen immunotherapy. Patient Prefer Adherence. 2008;2:247-251.

34. Kiel MA, Roder E, Gerth van Wijk R, Al MJ, Hop WC, Rutten-van Molken MP. Real-life compliance and persistence among users of subcutaneous and sublingual allergen immunotherapy. $J$ Allergy Clin Immunol. 2013;132:353-360.

35. Aschemann U, Schulte P, Hecker H. Examination of the compliance of a user-friendly allergoid [German]. Allergo J. 2010; 19(suppl 1):S63.

36. Senna G, Lombardi C, Canonica GW, Passalacqua G. How adherent to sublingual immunotherapy prescriptions are patients? The manufacturers' viewpoint. J Allergy Clin Immunol. 2010;126:668-669.

37. Vita D, Caminiti L, Ruggeri P, Pajno GB. Sublingual immunotherapy: adherence based on timing and monitoring control visits. Allergy. 2010; 65:668-669

38. Tworek D, Bochenska-Marciniak M, Kuprys-Lipinska I, Kupczyk M, Kuna P. Perennial is more effective than preseasonal subcutaneous immunotherapy in the treatment of seasonal allergic rhinoconjunctivitis. Am J Rhinol Allergy. 2013;27:304-308.

39. Distler A, Meijerman A, Kleinjans HA. Safety and clinical efficacy of an allergoid depot preparation in children and adolescents in daily practice. Allergy. 2010;65(suppl 92):S574.

40. Horne R, Weinman J, Barber N, Elliott R, Morgan M. Concordance, Adherence and Compliance in Medicine Taking: Report for the National Co-ordinating Centre for NHS Service Delivery and Organisation R\&D (NCCSDO). 2005. Available from http://www.nets.nihr.ac.uk/_data/ assets/pdf_file/0007/81394/ES-08-1412-076.pdf

41. Brozek JL, Akl EA, Alonso-Coello P, et al. Grading quality of evidence and strength of recommendations in clinical practice guidelines. Part 1 of 3. An overview of the GRADE approach and grading quality of evidence about interventions. Allergy. 2009;64(5):669-677.
Patient Preference and Adherence

\section{Publish your work in this journal}

Patient Preference and Adherence is an international, peer-reviewed, open access journal that focuses on the growing importance of patient preference and adherence throughout the therapeutic continuum. Patient satisfaction, acceptability, quality of life, compliance, persistence and their role in developing new therapeutic modalities and compounds to optimize

\section{Dovepress}

clinical outcomes for existing disease states are major areas of interest for the journal. This journal has been accepted for indexing on PubMed Central. The manuscript management system is completely online and includes a very quick and fair peer-review system, which is all easy to use. Visit http://www. dovepress.com/testimonials.php to read real quotes from published authors. 